\title{
Evaluation of Continuous Contour Trenches: A Case Study
}

\author{
S. S. Pendhare, H. N. Bhange*, S. V. Pathak, P. R. Kolhe, R. M. Dharaskar, \\ P. B. Bansode, M. H. Tharkar and G. G. Kadam \\ Department of Soil and Water Conservation Engineering, College of Agricultural Engineering \\ and Technology, DBSKKV, Dapoli- 415 712, Dist. Ratanagiri, M.S., India \\ *Corresponding author
}

A B S T R A C T

Keywords

inorganic, nondegradable inputs, soil erosion, geographical area

Article Info

Accepted: 12 April 2021 Available Online: 10 May 2021
Water and soil are the two fundamental resources on which people rely for existence and development. The development of society is determined by its capacity to use these resources. Some of these resources may in time become exhausted or deteriorated. Gane is characterized by its hot and humid climate comes under Konkan region. This region comes under heavy rainfall with average annual rainfall $3500 \mathrm{~mm}$. The ambient temperature 7.5 ${ }^{\circ} \mathrm{C}$ to $38.5^{\circ} \mathrm{C}$, relative humidity varies from 55 per cent to 99 per cent in region. Continuous Contour Trenches structure are rain water harvesting structures which is used for improve soil moisture profile. It also recharges groundwater by infiltration provides water and during lean seasons. Continuous contour Trenches structure helps to improve the living conditions of farmers. These types of water harvesting structures are economically and socially acceptable. Thus, continuous contour Trenches are found to play a major role in the agricultural production, particularly during summer season.

\section{Introduction}

Soil and Water Conservation Engineering is the application of engineering principles to the solution of soil and water management problems. The main objectives of soil and water conservation measures are to control and thus prevent loss of soil by soil erosion, to reduce soil compaction, to maintain or to improve soil fertility, to conserve or drain water, to harvest water. Land degradation together with pressure of ever growing demands for food, fuel and fiber from such lands is intensifying the problem and putting extra burden on limited resources. Adoption of intensive cultivation technologies and use of inorganic, non-degradable inputs for production, particularly from degraded lands 
is further aggravating the problem. It has been estimated by various agencies that out of 329 $\mathrm{m}$ ha total geographical area of the country; the area under degraded lands is between 63.9 to $187.0 \mathrm{~m}$ ha. However, a general consensus agrees at about $120.72 \mathrm{~m}$ ha. Degraded lands are characterized by low productivity potential due to various constraints related to rainfall management, soil, topography and biotic interference.

Contour trenching is an efficient technology for rehabilitation of degraded lands, particularly in semi-arid and arid regions where rainfall intensities are high and soils are sandy with relatively high permeability. It is very effective in revegetation of denuded land slopes and for development of orchards on sloping lands by reducing runoff and sediment loss and conservation of moisture for longer period in the soil profile.

It also helps in obtaining higher biomass productivity from watersheds due to improvement in physical and chemical properties of the soil Contour trenching in non-arable lands constitutes the single most popular measure and has been given the highest priority for the of sloping lands in the entire national and international watershed rehabilitation programs.

As agriculture is traditionally the major economic activity in Maharashtra, soil and water are two basic essentials for agriculture. Maharashtra is the third largest State in Union of India considering population as well as area. The population of the state is about 112 million. Nearly $58 \%$ of population lives in rural area which depends largely on agriculture for their livelihood. (Borse 2016). Due to soil erosion, water logging and other deteriorating factors nearly $50 \%$ of our cultivable land suffers from land degradation at various stages. If it is not checked the land will become waste land and unfit for cultivation. The degraded lands which have reached to severe stage of degradation are not under cultivation. If these lands are not treated immediately they will turn into waste land. Continuous Contour Trenches (CCT) was reported to decrease in the surface runoff by as much as $83.5 \%$ as compared to the untreated pasture used in Manola watershed development project, Akola, Maharashtra State of India (Bharad et al., 1993). Konkan region is characterized with high intensity rainfall, receives 46 per cent of rainfall of the Maharashtra state.

This region is geographically categorized under highly undulating with general slope ranging from 7 per cent to 35 per cent and average rainfall from 3500 to $4000 \mathrm{~mm}$ annually. The most reliable month of rainfall is July with the highest normality as 96.77 per cent (Bhange, et al., 2017). The structures were found to be having beneficial effect on water conservation in upstream area of the watershed. To harvest runoff and sediment load, for the present study Continuous contour trench (CCT) is considered as one of the soil and water conservation structure.

The main objectives of this study to design Continuous Contour Trenches structure by following standard design procedure.

\section{Design Components}

Design process of CCTs involves finding of the following specifications.

Horizontal and vertical interval between two CCTs. (spacing between two CCTs).

Cross Section of CCTs (Top Width, Bottom Width and Depth).

Choice of Plant Species.

\section{Design Principles}

Main principles for designing CCTs are as 
follows:

To make specifications site specific.

Flexibility in practice.

Smaller sections.

\section{Design Parameters}

Rainfall in that given area (High, Medium or Low)

Soil Type (Soil Infiltration Levels - Low/ Average and above / Medium)

Slope of the land.

Tree canopy planned/ exists in that region

\section{Design steps/formulae}

The designing of CCT is a function of/ dependent on the following design parameters.

\section{Finding Out Vertical Intervals (VI)}

VI: $0.305(\mathrm{X} \mathrm{S}+\mathrm{Y}) \ldots \ldots(1)$

Where,

$\mathrm{S}=$ Slope of the land in $\%$.

$\mathrm{X}=$ Rain Fall Factor (Refer Table No.1)

$\mathrm{Y}=$ Factor due to soil and type and canopy (Refer Table No.2)

\section{Finding out Horizontal Interval (HI)}

After determining the Vertical Interval (VI) from Step No.1, use the following formula for deriving HI.

$\mathrm{HI}=\frac{100 \times V I}{s} \ldots . .(2)$
Determining Dimensions of Trench: (Cross Section of Trench)

Cross section of the trench is to be determined keeping in view the runoff from the catchment of each trench and required storage capacity.

\section{Finding out catchment of each CCT}

Area drained between two trenches $=\mathrm{A}$

A=Average width between two trenches $x$ length of trench....(3)

\section{Fixing up dimensions of CCT}

Dimensions of Trench can be either Rectangular or Trapezoidal, depending on the nature of soil. Most generally adopted practice is to keep these sections small, as the main objective is to retain sufficient moisture in the soil to regenerate natural vegetation.

The following formula is used for determining the dimensions of the Trench.

$\mathrm{Q}=\frac{W \times D}{(100 \times H I)} \ldots .(4)$

Where,

$\mathrm{Q}=$ Depth of Runoff from catchment area of trench in $\mathrm{Cm}$.

$\mathrm{W}=$ width of trench $\mathrm{cm}$.

$\mathrm{HI}=$ Horizontal interval $\mathrm{m}$.

Normal practice is use square cross sections ranging from $30 \times 30$ to $50 \times 50 \mathrm{~cm}$

In case of trapezoidal section the side slope is 1:1.

\section{Calculation of Rainfall Intensity}

Hydrological design of flood control 
structures is done by computing the runoff rate for 25 to 30 years return period. (Suresh R, 2002). Intensity-duration-frequency equation developed for Chiplun(Maharashtra) was used: (Savane and Kubal, 2005)

$\mathrm{I}=\frac{7.9932 T^{0.1814}}{(t+1.0)^{0.811}} \ldots \ldots .(5)$

Where,

$\mathrm{I}=$ Rainfall intensity, $\mathrm{cm} / \mathrm{hr}$

$\mathrm{T}=$ Return period year

$\mathrm{t}=$ duration, $\mathrm{hr}$

By using this equation the rainfall intensity for any duration "t" up to 24 hours and any return period "T" up to 100 years can be determined.

\section{Calculation of Time of concentration}

Kirpich equation can be used for finding the time of concentration in minutes. This equation is as follows:

$\mathrm{t}_{\mathrm{c}}=0.00032 \mathrm{~L}^{0.77} \mathrm{~S}^{-0.385}$

Where,

$\mathrm{tc}=$ Time of concentration, minutes.

$\mathrm{L}=$ Maximum length of travel of water, $\mathrm{m}$

$\mathrm{S}=$ Slop of catchment $\mathrm{m} / \mathrm{m}$.

\section{Calculation of peak Runoff}

Singh et al., (2006) reported that Rational method was the oldest, simple and possibly the most consistence to estimate peak runoff rate. The method is expressed by using equation.

$\mathrm{Q}_{\mathrm{P}}=\frac{\text { CIA }}{36}$
Where,

$\mathrm{Q}_{\mathrm{p}}=$ peak rate off runoff, $\mathrm{m}^{3}$

$\mathrm{C}=$ Runoff coefficient

$\mathrm{I}=$ Intensity of Rainfall, $\mathrm{cm} / \mathrm{Hr}$

$\mathrm{A}=$ Area of watershed, ha

\section{Calculation of storage capacity of trench}

$\mathrm{Q}=\mathrm{L} \times \mathrm{W} \times \mathrm{D}$

Where,

L=length, $\mathrm{m}$

W=width, $\mathrm{m}$

$\mathrm{D}=$ depth, $\mathrm{m}$

\section{Materials and Methods}

This chapter resents Techniques and methodologies adapted to design and to evaluate Continuous contour Trench elected for study.

The structure was constructed during year 20015-2016 in Gane Watershed by the Department of Agriculture, Government of Maharashtra.

\section{Location}

Chiplun (Gane) taluka latitude is $17^{\circ} 32^{\prime} 0.20^{\prime \prime} \mathrm{N}$ and longitude $73^{\circ} 30^{\prime} 33.66^{\prime \prime} \mathrm{E}$

\section{Rainfall Data}

The total annual rainfall of Chiplun Tahasil for the period 2001-2018 is presented below. 
Design details of continuous contour trench of Gane watershed

\section{Measurement of slope of land}

The Hydro marker is used for measuring slope of the land. CCT should be constructed where slope is not more than $33 \%$.

\section{Runoff coefficient Estimation}

Type of structure - continuous contour Trench

Soil classification - sandy loam

Slope of land $-10.53 \%$

Runoff coefficient- 0.3

\section{Time of concentration Estimation}

Maximum length of $\operatorname{runoff}(\mathrm{L})=100 \mathrm{~m}$

Slope $=10 \%$

Time of concentration $\left(t_{c}\right)$

$\mathrm{t}_{\mathrm{c}}=0.00032(\mathrm{~L})^{0.77}(\mathrm{~s})^{-0.385}$

Where

$\mathrm{tc}=$ time of concentration, $\mathrm{h}$

$\mathrm{L}=$ length of stream, $\mathrm{m}$

$\mathrm{S}=$ watershed gradient $\mathrm{m} / \mathrm{m}$

$\mathrm{t}_{\mathrm{c}}=0.0032(100)^{0.77} \times\left(\frac{1}{10}\right)^{-0.385}$

$=0.0269 \mathrm{~h}$

\section{Rainfall intensity}

"I" for Gane for given duration and return period of 25 years
$\mathrm{I}=\frac{7.9932 \times T^{0.1814}}{(t+1.0)^{0.811}}$

$\mathrm{I}=14.01 \mathrm{~cm} / \mathrm{hr}$

\section{Peak runoff rate}

By Rational formulae, $\mathrm{Q}_{\mathrm{p}}$

$\mathrm{Q}_{\mathrm{p}}=\frac{C I A}{36}$

$=\frac{0.3 \times 14.01 \times 2}{36}$

$\mathrm{Q}_{\mathrm{p}}=0.2325 \mathrm{~m}^{3} / \mathrm{sec}$

Depth of runoff from catchment area of $\operatorname{trench}(Q)$

$\mathrm{Q}=\frac{(W \times D)}{100 \times H I}$

Where,

$\mathrm{Q}=$ depth of runoff from catchment area of trench, cm

$\mathrm{W}=$ width of trench, $\mathrm{cm}$

$\mathrm{D}=$ Depth of trench, $\mathrm{cm}$

$\mathrm{HI}=$ Horizontal interval, $\mathrm{m}$

$\mathrm{Q}=\frac{(60 \times 40)}{100 \times 15.08}$

$\mathrm{Q}=1.5 \mathrm{~cm}$

$\mathrm{Q}=0.015 \mathrm{~m}$

\section{Computation of direct runoff Depth}

The curve number method is used to compute the direct runoff (depth).This method is method is based on the potential retention capacity(S) of the watershed., which is 
determined based on the wetness of the watershed, i.e the antecedent moisture condition and physical characteristics of the watershed.

Weighted curve no of watershed

$$
\begin{aligned}
& =\frac{2 \times 47}{2} \\
& =47
\end{aligned}
$$

This computed weighted curve number is valid for AMCll.

Max. retention capacity (s) of the watershed, by using formula,

$\mathrm{CN}=\frac{2540}{25.4+5}$

$47=\frac{2540}{25.4+5}$

$\mathrm{S}=28.64 \mathrm{~cm}$

$\mathrm{Q}=\frac{(p-0.2 s)^{2}}{p+0.8 s}$

$=\frac{[40-0.2(28.64)]}{40+0.8(28.64)}$

$\mathrm{Q}=0.54 \mathrm{~cm}$

Where,

$\mathrm{Q}=$ Direct runoff

$\mathrm{S}=$ retention capacity of the watershed

$\mathrm{P}=$ Rainfall depth

$\mathrm{CN}=$ curve no

Determination of Total volume off runoff:

$\mathrm{V}=\mathrm{Q} \times \mathrm{A}$
$\mathrm{V}=0.0054 \times 20000$

$\mathrm{V}=108 \mathrm{~m}^{3}$

Measurement of Distance between two contour lines

The Hydromarker is used to draw the contour lines. The distance between two contour lines is depends upon the slope of the land.

\section{Measurement of length}

The length of rectangular CCT depends upon the slope of the land.

\section{Measurement of width}

The width of CCT is taken as $60 \mathrm{~cm}$.

\section{Measurement of depth}

The depth of CCT. varies between 30 to $45 \mathrm{~cm}$ depend upon the volume of runoff and slope of land, type of soil etc.

\section{Results and Discussion}

The design dimensions of the structure were calculated by using methodology as described below. The desired and existing dimensions of continuous contour trench are more or less same except length and depth of the trench. Department of Agriculture considered the depth of trench is $45 \mathrm{~cm}$ and Desired depth are $30 \mathrm{~cm}$. The peak rate of runoff $\left(0.23 \mathrm{~m}^{3} / \mathrm{s}\right)$ for the design of continuous contour trench was computed by using rational methods.

\section{Capacity of Continuous Contour Trenches-}

Capacity of CCT was calculated using following formula. It is given in point. It was obtained $334.8 \mathrm{~m}^{3}$ or 334800 litre. Total cost of construction of continuous contour trench for various kind of work was around Rs.59384. 
Table.1 Rainfall Factor X

\begin{tabular}{|c|c|}
\hline Rainfall & Value of $\mathbf{X}$ \\
\hline Below 625 & 0.8 \\
\hline 625-875 & 0.6 \\
\hline More than 875 & 0.4 \\
\hline
\end{tabular}

(WASSAN, 2000)

Table.2 Value of Y

\begin{tabular}{|c|c|c|}
\hline Soil Infiltration & Crop canopy cover during erosive Rain & Value of Y \\
\hline Low(Heavy soil) & Low & 1.0 \\
\hline Average and above & Good & 2.0 \\
\hline Medium & Medium & 1.5 \\
\hline
\end{tabular}

(WASSAN, 2000)

Table.3

\begin{tabular}{|c|c|c|}
\hline Sr. No & Description & Continuous ContourTrenches \\
\hline 1 & Watershed Location & Gane \\
\hline 2 & Distance from Chiplun & $15 \mathrm{~km}$ \\
\hline 3 & Year of construction & 2017 \\
\hline 4 & Water storage $\mathrm{m}^{3}$ & 500 \\
\hline 5 & Taluka & Chiplun \\
\hline 6 & District & Ratnagiri \\
\hline
\end{tabular}

Table.4 Measurement of distance between two contour lines

\begin{tabular}{|c|c|}
\hline Slope\% & Distance(m) \\
\hline $0-4$ & 10 \\
\hline $4-8$ & 8 \\
\hline $8-15$ & 6 \\
\hline $15-33$ & 4 \\
\hline \multicolumn{2}{|c|}{ (Daniel Sussman) } \\
\hline
\end{tabular}

Table.5 Measurement of length of CCT

\begin{tabular}{|c|c|}
\hline Slope \% & Length(m) \\
\hline $0-4$ & 100 \\
\hline $4-8$ & 50 \\
\hline $8-15$ & 30 \\
\hline $15-33$ & 20 \\
\hline
\end{tabular}


Table.6 Abstract of Earthwork for CCT

\begin{tabular}{|c|c|c|c|c|c|c|}
\hline \multirow{2}{*}{$\begin{array}{c}\text { Sr } \\
\text { No. }\end{array}$} & Item & Rate/unit & \multicolumn{2}{|c|}{ Desired } & \multicolumn{2}{|c|}{ Existing } \\
\cline { 4 - 7 } & & Quantity & Amount Rs. & Quantity & Amount Rs. \\
\hline $\mathbf{1}$ & Cleaning the site & & & 2000 & & 4000 \\
\hline $\mathbf{2}$ & Border marking & 181 & 2 M day & 362 & 2 M day & 362 \\
\hline $\mathbf{3}$ & $\begin{array}{c}\text { CCT and gap } \\
\text { marking }\end{array}$ & 181 & 8.34 & 1509 & 8.34 & 1509 \\
\hline $\mathbf{4}$ & $\begin{array}{c}\text { Excavation of } \\
\text { CCT }\end{array}$ & 31.25 & 334.8 & 10462 & 500 & 15609 \\
\hline $\mathbf{5}$ & $\begin{array}{c}\text { Pitching with } \\
\text { available stone }\end{array}$ & 181 & 250 & 40250 & 255 & 46227 \\
\hline $\mathbf{6}$ & $\begin{array}{c}\text { Material } \\
\text { Rs8/100R.m }\end{array}$ & 8 & 33.32 & 266 & 33.32 & 266 \\
\hline & \multicolumn{2}{|c|}{ Total } & & $\mathbf{5 4 8 4 9}$ & & $\mathbf{6 3 9 7 0}$ \\
\hline
\end{tabular}

Table.7 Cost Estimation for CCT

\begin{tabular}{|c|c|c|c|}
\hline Sr.No & Description & $\begin{array}{c}\text { Desired Amount } \\
\text { (Rs) }\end{array}$ & $\begin{array}{c}\text { Existing Amount } \\
\text { (Rs) }\end{array}$ \\
\hline $\mathbf{1}$ & Abstraction of earthwork & 54849 & 63973 \\
\hline $\mathbf{2}$ & Provision for work insurance 1\% & 735.84 & 765.84 \\
\hline $\mathbf{3}$ & Additional contegency 5\% & 3550 & 3829 \\
\hline $\mathbf{4}$ & Charge for land management & 150 & 150 \\
\hline $\mathbf{5}$ & Photo fee & 100 & 100 \\
\hline & Total & $\mathbf{5 9 3 8 4}$ & $\mathbf{6 8 8 1 8}$ \\
\hline
\end{tabular}

Table.8 Desired and Existing Dimensions of CCT

\begin{tabular}{|c|c|c|c|c|c|c|}
\hline Sr. & \multirow{2}{*}{ Description } & Unit & \multicolumn{5}{|c|}{ Dimensions } \\
\cline { 4 - 7 } & & \multicolumn{2}{|c|}{ Desired } & 2 & 2 \\
\hline $\mathbf{1}$ & $\begin{array}{c}\text { Treatment } \\
\text { Area }\end{array}$ & $\mathrm{Ha}$ & 2 & 2 & 2 & 54 \\
\hline $\mathbf{2}$ & $\begin{array}{c}\text { Size of } \\
\text { trench }\end{array}$ & $1 \times \mathrm{b} \times \mathrm{d}, \mathrm{m}$ & $30 \times 0.6 \times 0.3$ & $20 \times 0.6 \times 0.3$ & $20 \times 0.6 \times 0.45$ & $5 \times 0.6 \times 0.45$ \\
\hline $\mathbf{3}$ & $\begin{array}{c}\text { No of } \\
\text { trenches }\end{array}$ & $2 \mathrm{ha}$ & 62 & 94 & 94 & 370 \\
\hline $\mathbf{4}$ & $\begin{array}{c}\text { Volume of } \\
\text { one trench }\end{array}$ & $\mathrm{m}^{3}$ & 5.4 & 3.6 & 4.8 & 1.25 \\
\hline $\mathbf{5}$ & $\begin{array}{c}\text { Total } \\
\text { volume of } \\
\text { trenches }\end{array}$ & $\mathrm{m}^{3}$ & 334.8 & 338.4 & 451.2 & 500 \\
\hline
\end{tabular}


Fig.1 Continuous Contour Trench at Gane

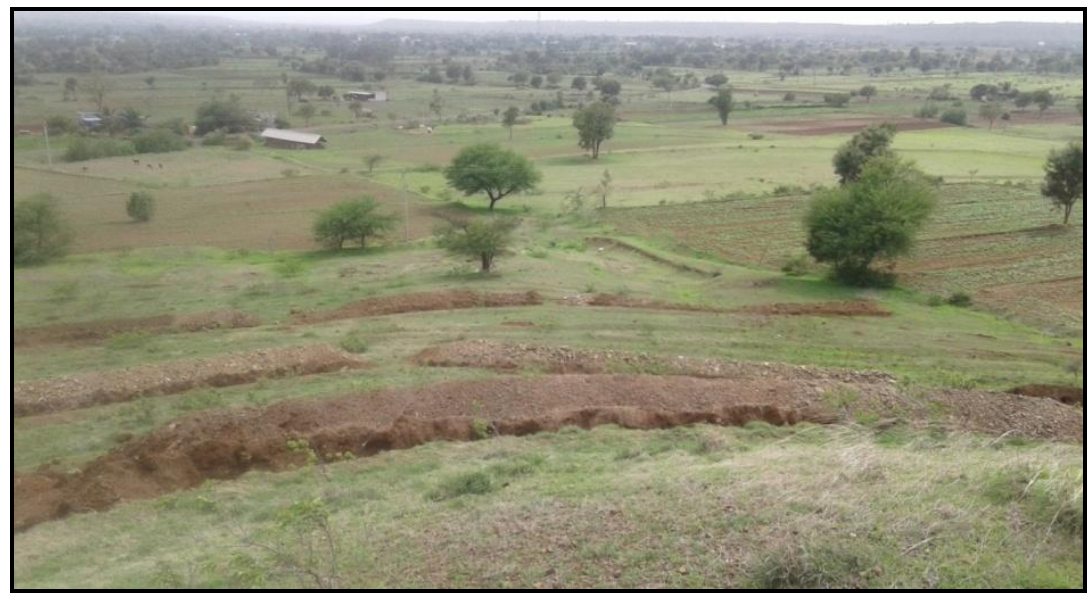

Fig.2 Annual Rainfall of chiplun

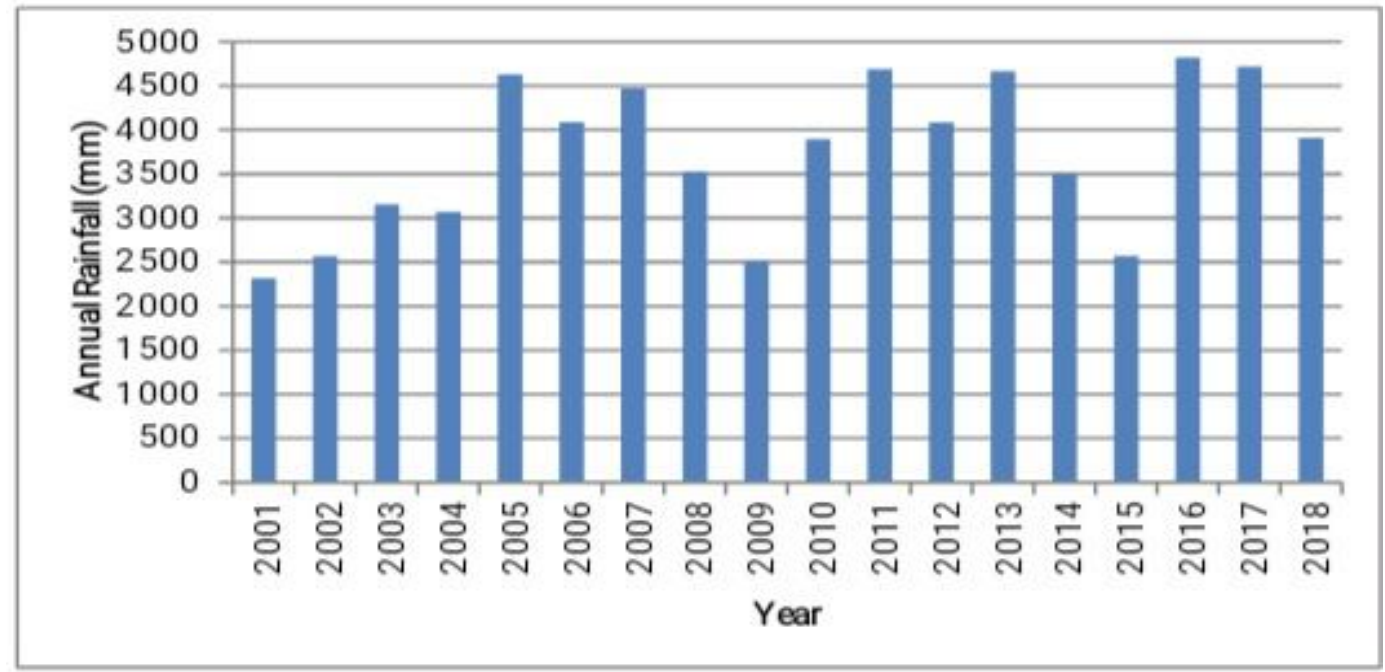

The study was undertaken to evaluate the soil and water conservation structures Continuous contour trench constructed by the Department of Agriculture, Maharashtra State. The continuous contour trench at-Gane watershed Situated in Chiplun Tahsil of Ratnagiri District was selected for study.

For continuous contour trench peak discharge calculated by Rational method was $0.2325 \mathrm{~m} 3 / \mathrm{s}$.

The cost of construction of existing continuous contour trench was found to be higher than the cost calculated for the structure designed by standard design procedure.

Construction of CCT helps in increasing the groundwater level and water level in nearby wells situated at the downhill where CCT are constructed.

Continuous Contour Trench create more favourable moisture condition.

The cost of construction of continuous contour trench computed by department of agriculture 
was found to be $15.88 \%$ higher than the desired cost.

CCT technique should be used on large scale at wider part of Maharashtra to solve the soil and water conservation.

In Konkan region more runoff is expected so we can increase the large water harvesting structure like Deep CCT and water absorption Trenches etc.

Vegetation is very necessary where slope is more.

\section{References}

Bhange. H. N., D. M Mahale, R. V. Pawar and S. S. Palekar (2017) Runoff, Suspended Sediment and Erosion Rate in the Priyadarshini Watershed. Anthology : The Research Vol-2 Issue4, 14-20.

Bharad G. M., M. B. Nagdeve, S. K. Kohale, S. M. Taley, A. N. Mankar, S. N. Ingle, S. N. Patil (1993) Watershed
Management Research. Watershed Management Research Unit Dr. Panjabrao Deshmukh Agricultural University, Akola, India

Borse, N. B. (2016) Importance of Continuous Contour Trenches (CCT) in Maharashtra, A seminar on Sustainable Development of Water resource in Maharashtra State.

Daniel Sussman, Design Manual: Contour Trenches, Bren School of Environmental Science and Management, University of California Santa Barbara.

Suresh, R. 1997. Soil and Water Conservation Engineering, Standard Publishers Distributors, Delhi.Tideman, E.M. 2003. Watershed Management Guideline for Indian Conditions, Omega Scientific Publisher, New Delhi, pp 92- 95.

WASSAN, 2000. "Report of the Study Team on Continuous Contour Trenches" An unpublished document by WASSAN, Hyderabad.

\section{How to cite this article:}

Pendhare, S. S., H. N. Bhange, S. V. Pathak, P. R. Kolhe, R. M. Dharaskar, P. B. Bansode, M. H. Tharkar and Kadam, G. G. 2021. Evaluation of Continuous Contour Trenches: A Case Study. Int.J.Curr.Microbiol.App.Sci. 10(05): 368-377.

doi: https://doi.org/10.20546/ijcmas.2021.1005.044 